ARTIGOS

\title{
Filosofia e interdisciplinaridade
}

\section{Philosophy and interdisciplinarity}

Márcio José Silveira Lima i

i Universidade Federal do Sul da Bahia (UFSB), Porto Seguro, BA, Brasil. marsil@ufsb.edu.br/marscill@gmail.com

\begin{abstract}
Resumo
Este texto pretende discutir alguns aspectos da interdisciplinaridade, tendo como fio condutor duas ideias centrais: primeiro, a importância do tema para os debates em torno da construção e da transmissão do conhecimento; segundo, a delimitação do campo de reflexão em que a contraposição à especialização ganha especial destaque. A intenção é questionar se a crítica à especialização não é contemporânea da própria consolidação do trabalho disciplinar e dos especialistas; e se essa crítica não teria aberto o caminho para os debates sobre a interdisciplinaridade. Nesse caso, escolheram-se três filósofos que parecem corroborar esse ponto de vista: Ortega y Gasset, Nietzsche e Adorno. Nos três casos, pode-se perceber a defesa da necessidade de abertura para um conhecimento mais amplo. Por fim, esboçam-se alguns pontos relevantes sobre a filosofia como uma disciplina e sobre o lugar que a crítica à especialização ocupa em sua reflexão, e conjectura-se sobre a abertura para o trabalho interdisciplinar.
\end{abstract}

Palavras-chave: filosofia, formação, especialização, interdisciplinaridade

\section{Abstract}

This paper aims to discuss some aspects of interdisciplinarity, by a single thread two central ideas: first, the importance of the issue to questions relating to knowledge; second, the delimitation of the field of reflection in which opposition to the specialization gained special prominence. The intention is to question whether the criticism of specialization is not contemporary consolidation of own disciplinary work and specialists, and this criticism would not have opened the way for discussions on interdisciplinarity. In this case, we chose threephilosophers who seem to corroborate this view: Ortega y Gasset, Nietzsche and Adorno. In all three cases, we can see a defense of the need for openness to a broader knowledge. Finally, we intend to outline some relevant points about philosophy as a discipline and the place that the criticism of specialization takes in its reflection and how it would be opening for interdisciplinary work.

Keywords: philosophy, training, specialization, interdisciplinarity 


\section{pro.posıções}

\section{Introdução}

Somos sempre tentados a afirmar que, em nossos dias, a crítica à especialização e o debate em torno da interdisciplinaridade e por sua busca são ubíquos, dir-se-ia temas que se repetem nos meios acadêmicos praticamente como um ostinato. Todavia, nascendo quase simultaneamente com o tipo de formação na qual a especialização assume o papel central, a interdisciplinaridade, como o horizonte sobre o qual se revela a paisagem de crítica e combate a esse protagonismo dos especialistas, talvez já não possa ser considerada uma novidade pedagógica, uma forma recente com que os teóricos da educação propõem novas metodologias de construção do conhecimento e novas maneiras de orientação da prática de ensino. Se isso estiver correto, é necessário entender o que precisamente está em jogo quando se fala de interdisciplinaridade e por que ela se coloca como uma meta que, desde o seu nascedouro, busca combater a especialização. Por outro lado, a tentativa de dimensionar esse embate não deve servir apenas à causa de uma compreensão da interdisciplinaridade num sentido lato, mas também deve servir para o abandono de posicionamentos dogmáticos sobre a questão, o que, por si mesmo, parece já atentar contra o ideal de um conhecimento que preza pela diversidade e por um ensino que cultive a abertura de visão, e não por uma postura que promova uma caça às bruxas, atitude que algumas vezes a crítica à especialização corre o risco de adotar. Apontando para os limites e os perigos do saber especialista, a interdisciplinaridade deve ultrapassar a especialização, mantendo, porém, com ela um diálogo aberto, sem ressentimentos, e reconhecendo seus méritos e virtudes. Nesse aspecto, muitos filósofos desde muito cedo se levantaram contra os perigos que representa a especialização, seja da perspectiva de produção do conhecimento, seja da perspectiva de sua transmissão. Certamente o perfil da filosofia, cuja tradução estava expressa na fórmula "rainha das ciências", contribuiu para isso, uma vez que o trabalho filosófico sempre representou uma tentativa de síntese do conhecimento, não se prendendo a um ou a outro saber específico. Vejamos, então, exemplos de alguns autores que refletiram sobre a especialização e os limites de sua prática, tentando daí extrair elementos para pensar a interdisciplinaridade. 


\section{pro.posıções}

\section{Genealogia da especialização}

Quando se fala em interdisciplinaridade, somos levados com frequência a pensar nela como a saída para uma fragmentação do saber, a qual teria sido impelida pelo próprio advento da ciência moderna, cuja instauração e desenvolvimento necessitaram apontar para a concepção antiga de unidade do conhecimento e contra ela desferir o golpe que estilhaçaria o saber em partes ínfimas. Segundo Morin (1999), essa fragmentação, quase sempre atribuída ao ideal moderno de fundamentação de um conhecimento seguro, teria em Descartes um de seus principais arautos. Morin, em cuja obra se encontram preocupações constantes sobre o problema disciplinar, concebe que a filosofia cartesiana teria estabelecido uma das etapas fundamentais para a fragmentação dos saberes. Além da separação, princípio formulado no interior do método cartesiano, haveria outros três princípios: ordem, redução e a validade absoluta da lógica clássica.

Todavia, se a interdisciplinaridade hoje é, nas palavras de Gusdorf (1995), a panaceia epistemológica que vai resolver nossos problemas, é possível considerar que as questões que fizeram surgir a necessidade de superação de um conhecimento extremamente especializado como o nosso não são privilégio de nossa época. A busca por uma unidade do saber e do conhecimento é mais antiga que o surgimento da divisão analítica proposta por Descartes e, mesmo quando esta se tornou "protagonista", nunca reinou soberana por muito tempo. O próprio Descartes, a cujo método se costuma atribuir uma grande responsabilidade pela consolidação de um saber dividido, disciplinar e especializado, pensou um modelo de ciência que tinha por alvo último a unidade do saber, e não apenas sua divisão.

Embora o termo "interdisciplinaridade" tenha sido introduzido na segunda metade do século XX, especialmente por Piaget (1970) e pelos congressos promovidos pela Unesco (Fazenda, 2011; Gusdorf, 1995), os problemas que constituíram o solo fértil que permitiu germinar a interdisciplinaridade já haviam sido apontados bem antes. Ainda que a interdisciplinaridade não se reduza ao confronto com a especialização, talvez seja o apelo mais evidente que se tem em mente, quando se aborda a questão. Nesse aspecto, é digno de nota que o diagnóstico que revela os limites do tipo de formação tal como a do especialista, é quase contemporâneo ao surgimento da própria especialização1. Em contrapartida, na

\footnotetext{
1 Um exemplo de que houve quem logo percebesse os limites da especialização da ciência foi Ludwig von Bertalanffy, que propôs sua teoria dos sistemas como forma de resolução dos problemas impostos pela realidade, cujas metodologias disciplinares não seriam capazes de resolver. Segundo o autor, já na década de 1920, insatisfeito com a concepção mecanicista da natureza, ele buscou uma extensão de áreas como a
} 


\section{pro.posições}

história das ideias, bem como no ideal de formação e de educação, não faltam elogios a uma forma de conhecimento que preza pela abrangência e pela pluralidade, o que nos motiva a pensar que a especialização, mesmo antes de seu surgimento e de seu domínio do saber, sempre foi vista como um perigo a ser evitado2.

Nos anos 30 do século XX, Ortega y Gasset escreveu sobre os perigos da especialização, buscando compreender quais causas engendraram um tipo de formação em que se sabe muito de quase nada. A sua fórmula do sábio-ignorante já é de certa forma conhecida e, por isso mesmo, gostaria de ater-me à sua reflexão sobre o processo histórico que conduziu a ciência a essa situação. Segundo o filósofo espanhol, o advento singular da união entre ciência e técnica, que só teve vez no Ocidente, fez surgir um conhecimento cujo progresso e desenvolvimento só foram possíveis graças à especialização. Distinguindo entre a constituição e o desenvolvimento científico, ele nota que constituir a física experimental como ciência foi um trabalho que se iniciou no século XVI com Galileu e foi terminado por Newton e seus contemporâneos no século XVIII. Mas esse esforço de unificação de vários campos sob uma mesma rubrica, para avançar e progredir, precisou especializar-se.

físico-química, a cinética e a termodinâmica tradicionais, generalizando-as de modo que, em 1937, quando apresentou sua "teoria geral dos sistemas", não teve uma boa recepção. Somente após o término da Segunda Guerra, quando outras teorias abrangentes, como a cibernética, a teoria da informação e dos jogos já eram conhecidas, é que ele pôde expor sua teoria. Bertalanffy (1969) explica que suas construções são modelos teóricos ampliados e generalizados que transcendem os departamentos tradicionais e se aplicam a fenômenos em diversos domínios. Fazer essa generalização implica conceber novas categorias do pensamento, e os modelos introduzidos para satisfazer essa necessidade só podem ser de natureza interdisciplinar (p. 94).

2 Georges Gusdorf, por exemplo, afirma que a importância da interdisciplinaridade pode ser percebida pela frequência com que o termo aparece nos debates na universidade, nos quais ninguém se arriscaria a pronunciar-se contra ela. Ela é a panaceia epistemológica que vai curar os males que afetam a consciência acadêmica de nosso tempo. Todavia, essa não é uma descoberta recente. Em seu entender, a ideia de interdisciplinaridade já está presente na educação grega dos sofistas com sua noção de enkuklios paideia, isto é, um ensino circular que deve levar o estudante a um exame geral de todas as disciplinas constitutivas da ordem intelectual. Segundo Gusdorf, é esse mesmo programa de uma pedagogia da totalidade que vai ser sempre retomado ao longo da história em diferentes perspectivas de formação - tais como as artes liberais com o trivium e o quadrivium, na Idade Média -, cuja renovação ocorreria com os renascentistas e que seria adotado pelos colégios jesuítas. Além desses testemunhos, ele cita o Museu de Alexandria, projeto de reagrupamento das artes e das ciências, e Plínio, o naturalista, para quem a natureza só pode ser contemplada em sua totalidade e não por suas partes, palavras que seriam usadas como epígrafe por Alexandre Humboldt em sua principal obra, Kosmos, de 1844. Cometendo um anacronismo terminológico, Gusdorf (1995) atribui a todas essas experiências da totalidade do saber um ideal de formação interdisciplinar. Como quer que seja, seu argumento central consiste justamente em mostrar que o problema em torno do qual a interdisciplinaridade surge e é constantemente invocado não é novo. Ele faz parte da própria história da educação (pp. 7-8). 


\section{pro.posıções}

Para progredir, a ciência necessitava que os homens de ciência se especializassem. Os homens de ciência, não ela mesma. A ciência não é especialista. Ipso facto deixaria de ser verdadeira. Nem sequer a ciência empírica, tomada em sua integridade, é verdadeira se se separa da matemática, da lógica, da filosofia. Mas o trabalho nela tem de ser inevitavelmente - especializado. Seria de grande interesse e mais útil que aparentemente, à primeira vista, fazer uma história das ciências físicas e biológicas, mostrando o processo de crescente especialização no trabalho dos pesquisadores. (Ortega y Gasset, 1966, p. 216)

Essa especialização necessária para o progresso da ciência, prossegue o filósofo, teve seu início decisivo no século XIX. Há, pois, uma geração de homens da ciência, cuja produção já é a de um especialista, embora seu saber ainda seja enciclopédico. Entendemos, dessa forma, que os homens dessa geração já praticavam uma ciência especializada, mas não eram fechados em seu pequeno pedaço de universo que era o seu objeto de pesquisa. Podemos pensar em um botânico, que já conhece bastante das espécies a que se dedica, mas ainda sabe idiomas, línguas clássicas, lê literatura e tem também conhecimento do que se passa em outras áreas do saber. Contudo, essa geração seria sucedida por uma nova, a dos homens dos fins do século XIX, que, assumindo o controle intelectual da Europa, cujo perfil revelou que eles só conhecem uma ciência determinada, aquela que pratica, e mesmo assim somente um pedacinho dela. Esse homem tem orgulho de apenas compreender aquilo que pesquisa e considera mero diletantismo julgar ou querer saber algo para o qual não se especializou. Se é inegável que, para evoluir, a ciência moderna precisou da especialização, também é forçoso admitir os limites que a estreiteza de visão de seus homens acabou impondo ao próprio trabalho científico.

Ortega y Gasset (1966) identifica aquilo que poderíamos denominar de um movimento circular que delineia o trajeto do desenvolvimento científico. Ora, a especialização, necessária para o progresso da ciência, é a exigência de um trabalho maior desempenhado por aqueles que têm uma visão ampla e capaz de unificar os saberes. Em suas palavras, a ciência

necessita de tempo em tempo, como uma regulamentação orgânica de seu próprio incremento, de um trabalho de reconstituição, e, como eu disse, isso requer um esforço de unificação, cada vez mais difícil, que cada vez complica regiões mais vastas do saber total. Newton conseguiu criar seu sistema físico sem saber muita filosofia; mas Einstein precisou saturar-se de Kant e de Mach para conseguir chegar a sua aguda síntese. Kant e Mach - com esses nomes se simboliza somente a massa enorme de pensamentos filosóficos e psicológicos que influenciaram Einstein - eles serviram para liberar sua mente e deixar-lhe o caminho livre para a sua inovação [destaque nosso]. Mas Einstein não é suficiente. A física entrou na crise mais profunda de sua história e somente pode salvar-se com uma nova enciclopédia mais sistemática do que a primeira. O especialismo, portanto, que tornou possível o progresso da ciência experimental durante um século, se aproxima de uma etapa em que não pode avançar por si mesmo se não se encarrega uma geração melhor de construir-lhe um novo instrumento mais poderoso (p. 220). 


\section{pro.posições}

Ora, porque os limites da especialização consistem em períodos de crise da ciência, de questionamentos dos modelos, o homem da ciência, preso a seu pequeno pedaço do mundo de que sabe muito - embora ignore todo o resto -, não é capaz de indicar o caminho para a superação das aporias, precisamente porque só uma visão ampla lhe daria essa condição, e isso lhe falta. Não há como não reconhecer nesse diagnóstico de Ortega y Gasset uma semelhança com a visão de Thomas Kuhn sobre a história da ciência, com suas teses sobre a ciência normal, seus períodos de crises e anomalias, assim como o engendramento de um novo paradigma (Kuhn, 2001). No movimento circular do desenvolvimento da ciência, se a especialização desempenha, por um lado, um papel fundamental, na medida em que é responsável por fazer progredir as teorias e os paradigmas, por outro lado, por não cultivar essa visão acima de sua mera capacitação, faria a própria ciência retroceder diante dos problemas que os momentos inevitáveis de crise de ciência colocam. Daí a afirmação de Ortega y Gasset de que a crise por que passava a física em sua época só poderia ser superada por uma geração formada num ambiente diverso daquele do especialista, o qual só conhece um pequeno pedaço do mundo que estuda.

Esse diagnóstico nos permite ver o projeto filosófico de Descartes (1973) de uma perspectiva diversa daquela a que habitualmente estamos acostumados, especialmente quando se trata da busca pela unidade da ciência e da crítica à sua antípoda, a especialização. Primeiramente, porque o método cartesiano, apesar de ter como segunda regra a da divisão e análise, postula como quarta e última a da enumeração e síntese (p. 54). Em segundo lugar, porque o método, ele mesmo, tem como fundamento a lógica (filosofia), a álgebra (matemáticas) e a análise (geometria), sem cujos modelos não seria possível compreender a proposta cartesiana (p. 52). Em terceiro e último, ao pensar na aplicação do método e de como ele pode servir para bem conduzir a razão e dirigir o espírito, Descartes (2007, pp. 1-4) afirma que quem deseja conhecer a verdade não deve aplicar-se a uma ciência específica, pois todas elas estão ligadas por uma dependência mútua.

Desses três passos, o primeiro mostra que o método cartesiano não propõe apenas a divisão por meio da análise, como também a síntese por meio da enumeração. O segundo revela a integração dos saberes na composição do método. Por fim, o terceiro revela a unidade da razão em exercício, pela recusa em evitar a busca pelo conhecimento que hoje chamamos de disciplinar. Isso deveria nos fazer pensar se o caminho tomado pelo conhecimento não representa apenas uma face do projeto cartesiano e, sobretudo, se o próprio Descartes, cuja filosofia comumente é considerada um dos alicerces do saber 


\section{pro.posıções}

especializado, não rechaçava o isolamento dos saberes. Isso reforça a tese de que a especialização sempre encontrou resistências, mesmo por parte daquele que viu na análise o passo fundamental para bem conduzir a razão e procurar a verdade nas ciências.

\section{Para uma crítica da especialização}

Gostaríamos de discutir, nesta seção, alguns casos que revelam o efeito da sedimentação da formação do especialista, valendo-nos, para tanto, da ideia de Ortega y Gasset de que o século XIX representou o ápice dessa situação. Se nos ativermos à exposição do filósofo espanhol, é possível compreender com mais clareza esse processo de constituição do saber especialista. O caso Nietzsche é exemplar. Segundo Peter Sloterdijk, Nietzsche é um desses filósofos cuja obra não se pode separar do próprio autor que a criou. Ele nos lembra de aspectos importantes da biografia de Nietzsche, para dela tirar conclusões filosóficas que aqui nos interessam muito. Em 1869, aos 25 anos, Nietzsche conseguiu a cátedra de filologia clássica na Universidade de Basileia, por recomendação de seu mestre e professor Ritschl, um dos grandes nomes da filologia de sua época. Na carta de recomendação, depois de destacar os méritos do jovem indicado, ele conclui: "Você dirá que estou descrevendo um fenômeno; pois bem, é justamente isso o que ele é; e, além disso, é amável e modesto. Também um músico com talento, o que é irrelevante aqui" (Sloterdijk, 1989, p. 8 ). Ao contrário do que acreditava Ritschl, Sloterdijk não considera a informação irrelevante, pois ela é o ponto crucial da existência de Nietzsche e que representa a natureza singular de sua escritura. A maior atualidade de Nietzsche não seria sua inegável competência crítico-cultural, psicológica e filosófica, porém uma espécie de incapacidade.

A incapacidade mais profética de Nietzsche é que ele não pôde ser um especialista em nada; nunca se permitiu estar contente em fazer algo de uma maneira que fosse apenas correto profissionalmente; nunca pensou cumprir meramente essas expectativas. Não porque fosse incapaz de satisfazer os critérios de sua disciplina, mas o contrário.... Na verdade, o talento de Nietzsche não foi uma coleção de habilidades que se desenvolveram uma ao lado da outra; seus talentos na realidade não se separam uns dos outros, nem tampouco simplesmente coexistem. Ele foi muito mais que, em cada instância, um talento atuando através de outros, de modo que ele não foi, como muitos artistas, simultaneamente um artista e um músico, um poeta e um filósofo, um produtor e um teórico etc., mas antes um músico como escritor, um poeta como filósofo e um produtor como teórico. Ele não pratica uma habilidade ao lado de outras, mas pratica uma enquanto pratica outra. (Sloterdijk, 1989, p. 6) 


\section{pro.posıções}

Embora tenha sido formado na melhor tradição da filologia alemã, Nietzsche jamais praticou essa disciplina à maneira de um típico especialista da segunda metade do século XIX, mesmo tendo sido um aluno e um professor brilhantes. Essa habilidade de que fala Sloterdijk pode ser constatada quando analisamos $O$ nascimento da tragédia, primeiro livro de Nietzsche, bem como o contexto polêmico de sua publicação. À época em que ainda preparava a obra, Nietzsche escreveu uma carta (2003, p. 95) a seu amigo Erwin Rohde e nela afirma que está prestes a parir um centauro. Com efeito, partindo de uma questão motivada pelas investigações filológicas, Nietzsche acaba dando um tratamento bastante heterodoxo às suas teses. A reação ao livro foi imediata. Wilamowitz-Möllendorff, antigo colega de Nietzsche em Pförta, escreveu um panfleto denunciando $O$ nascimento da tragédia, acusando seu autor de não se comportar como um pesquisador científico, pois desprezava conhecimentos elementares da filologia, da história e da arqueologia, em nome de concepções artísticas e filosóficas. "O senhor Nietzsche não se apresenta como um pesquisador científico" (Wilamowitz-Möllendorff, 2005, p. 56).

A polêmica envolvendo a publicação de $O$ nascimento da tragédia é bem ilustrativa do panorama histórico-científico apresentado por Ortega y Gasset em seu texto, precisamente no que tange ao perfil dos homens do conhecimento no fim do século XIX. De um lado, temos um espírito como o de Nietzsche, formado numa perspectiva disciplinar de uma ciência humana bastante rigorosa já àquela época, como é o caso da filologia clássica; de outro lado, há um Willamowitz, também formado nessa mesma escola e dono de uma vasta erudição. Em um caso, há a evidência de um jovem erudito que se negava a praticar a ciência tal como exigia o receituário de sua época. Contra as muitas tendências de seu tempo, Nietzsche julgava-se um extemporâneo. De outro lado, um profundo conhecedor da Antiguidade clássica que acusava o primeiro de falta de rigor e, por que não dizer, de mero diletantismo por parte de alguém que pretendia ultrapassar os limites de sua própria disciplina e área do saber.

No caso de Nietzsche, mesmo antes de escrever $O$ nascimento da tragédia, ele já havia diagnosticado os problemas da formação de sua época num conjunto de palestras intituladas O futuro de nossos estabelecimentos de ensino e, em obras posteriores, como em Além do bem e do mal, critica a especialização como um dos sintomas modernos que apequenavam o homem. Por isso, afirma: 


\section{pro.posições}

Face a um mundo de ideias modernas, que gostaria de confinar cada um num canto e numa especialidade [Spezialität], um filósofo, se hoje pudesse haver filósofos, seria obrigado a situar a grandeza do homem, a noção de grandeza, precisamente em sua vastidão e multiformidade [Vielfältigkeit], em sua inteireza na diversidade. (Nietzsche, 1992, p. 119)

Nietzsche, porém, não desconsiderava o valor que o conhecimento de um especialista tem. Ele mesmo nunca deixaria de invocar sua formação de filólogo para denunciar a linguagem como uma das grandes responsáveis pelos abusos cometidos pela metafísica. E na Genealogia da moral, ao término da primeira dissertação, tendo analisado, da perspectiva da linguagem, o problema das dicotomias entre bom e mau e bom e ruim, vai concluir a primeira seção do livro invocando uma cooperação entre campos do saber que hoje, talvez, chamássemos de interdisciplinar. Vale a pena olhar com paciência a passagem:

Aproveito a oportunidade que me oferece esta dissertação para expressar pública e formalmente um desejo, desejo que até o momento revelei apenas em conversas ocasionais com estudiosos: que alguma faculdade de filosofia tome para si o mérito de promover os estudos histórico-morais; instituindo uma série de prêmios acadêmicos - talvez este livro [Genealogia da moral] possa dar um impulso vigoroso nesta direção. Tendo em vista tal possibilidade, propõe-se a questão seguinte; ela merece a atenção dos filólogos e dos historiadores, tanto quanto a dos profissionais da filosofia. "Que indicações fornece a ciência da linguagem, em especial a pesquisa etimológica, para a evolução dos conceitos morais?”. É igualmente necessário, por outro lado, fazer com que os fisiólogos e médicos se interessem por este problema (o do valor das valorações até agora existentes): no que pode ser deixado aos filósofos de ofício representarem os porta-vozes e mediadores também neste caso particular, após terem conseguido transformar a relação entre filosofia, fisiologia e medicina, originalmente tão seca e desconfiada, num intercâmbio dos mais amistoso e frutífero. (Nietzsche, 1998, pp. 45-46)

Vemos aí talvez um posicionamento diferente em relação ao saber disciplinar, a seus limites e ao chamado para o cruzamento das múltiplas perspectivas do saber. Já esse chamado aponta para a permanente desconfiança de Nietzsche em relação ao saber do especialista. Como mostra a passagem, o filósofo conclama para a reunião de muitas áreas do saber, no que tange à resolução do problema. Mas há que notar, também, que a motivação passa por um encontro em que a disciplinaridade é respeitada como um lócus próprio de metodologias individuais, as quais, no fim das contas, são convocadas para um trabalho colaborativo comum. Portanto, a crítica tardia de Nietzsche passa, por assim dizer, por uma tentativa mais modesta em relação à construção do saber a partir de uma perspectiva ampla. 


\section{pro.posições}

Se essa hipótese estiver correta, é possível que a forte crítica que recebeu quando escreveu $O$ nascimento da tragédia tenha sido decisiva para redimensionar sua visão sobre os limites da especialização e sua busca constante por um saber plural e aberto ao diálogo. Com efeito, enquanto na obra inicial havia a tentativa de explorar um problema a partir de uma vastidão de áreas do saber pelas quais o próprio filósofo seria responsável, na obra sobre a moral essa necessidade de abordar a questão de uma perspectiva ampla se apresenta pela invocação da necessidade de uma colaboração mútua. É possível, portanto, afirmar que aquilo que Nietzsche tomou como sua tarefa ele depois veria no compartilhamento do trabalho de investigação um caminho mais modesto e efetivo. De qualquer modo, reduzir seja qual for o tema ao trabalho do especialista é uma forma de apequenamento que o filósofo deve evitar.

Ponto de vista similar seria adotado por Adorno (2003), que também denunciou a relação seca e fechada entre as áreas do conhecimento. No texto chamado "A filosofia e os professores", analisando o papel do conhecimento filosófico que era exigido para os candidatos a professores de ciência, ele faz reflexões importantes sobre a relação entre os saberes. Criticando a própria diretriz da seleção, a qual aconselhava a não exigir do candidato um conhecimento específico de filosofia, Adorno afirma que a filosofia só faz jus a si mesma quando não é uma disciplina específica; por isso mesmo não se deveria impor aos estudantes "a deformação profissional daqueles que automaticamente consideram sua própria área de atuação como sendo o centro do mundo" (p. 53).

A despeito disso, se a especialização fere o espírito filosófico, não se deve pensar que a filosofia seja a rainha das ciências, como foi a pretensão desse saber por muito tempo. É preciso, alerta-nos Adorno, evitar mal-entendidos. Só quando a filosofia ganhou autonomia em relação às ciências naturais é que essas passaram por uma profunda evolução. E a própria filosofia ganhou muito quando não teve mais de ocupar-se com questões específicas dessas ciências, tendo atingido, ipso facto, apreciações mais profundas da realidade. Nesse movimento de independência das ciências diante da filosofia e da libertação da filosofia em relação às questões que hoje são objetos de estudo específicos de outras áreas, Adorno apresenta uma situação dupla. Por um lado, algumas ciências humanas, como a filologia, alcançaram um grau de reflexão tão desenvolvido que a filosofia pode parecer aos filólogos exercício de diletantes. Por outro lado, há inúmeros cruzamentos entre as reflexões produzidas pelas disciplinas, sem os quais o próprio conhecimento parece ser interditado. Assim, Adorno cita, por exemplo, que, para a compreensão das poesias de Schiller, é fundamental sua relação com Kant, sem a qual não se pode compreender inteiramente seus poemas e dramas. 


\section{pro.posições}

Poderíamos ainda acrescentar a essa relação a influência do próprio Schiller na música de Beethoven, cuja nona sinfonia termina com o famoso Coral entoando a Ode à alegria.

Há, pois, uma série de "linguagens" implicadas nas diferentes formas do saber, sem cujo conhecimento é impossível ter acesso aos pressupostos mais elevados que animam o espírito das obras. Nesse sentido, um estudante da obra de Schiller pode muito bem seguir sua trajetória desconhecendo filosofia e música, embora o autor que seja tema de seu estudo conceba sua obra a partir de reflexões filosóficas e, por sua vez, as ideias que essa mesma poesia expressa possam refletir na música de um compositor. Há uma série de relações, ideias e concepções conexas que uma separação dos saberes não pode atingir, considerando que essas áreas permaneçam fechadas em si mesmas. Se nem sempre é visível a necessidade de transitar nessa zona de fronteira onde é gerado aquilo que as disciplinas recortam como sua área de interesse, é certo que nenhuma apreensão da realidade pode prescindir dessa dimensão ampla e complexa. Romper com essa limitação deve ser sempre a preocupação de todo aquele que esteja interessado em pensar de forma interdisciplinar, e a filosofia, como julga Adorno, desde sempre ocupou aí um lugar de destaque.

\section{Filosofia e formação interdisciplinar}

Pela forma como se constituiu historicamente, parece natural que a filosofia tenha assumido uma posição crítica desde que a especialização começou a despontar absoluta na produção do conhecimento. Menos do que reivindicar um suposto lugar que lhe era de direito, trata-se antes de mostrar os limites a que levariam os caminhos da especialização. Foi, portanto, o olhar amplo dos filósofos que lhes permitiu ver uma certa estreiteza na forma de atuar dos especialistas. Dos exemplos que analisamos, podemos inferir três formas de abordar o problema da especialização: uma forte denúncia, revelando os perigos que ela representa à própria noção de ciência; um enquadramento de seu despontar como um sintoma da modernidade e, diante de sua irreversibilidade, a necessidade de abertura para o trabalho conjunto de diferentes pesquisadores; o elogio por ter feito as áreas do saber se constituírem de acordo com seus próprios métodos, multiplicando os saberes disponíveis, ao mesmo tempo em que se condena o fechamento nessas áreas como entrave a essa mesma 


\section{pro.posıções}

multiplicação. Essas três versões correspondem, como vimos, aos diagnósticos de Ortega y Gasset, Nietzsche e Adorno, respectivamente.

Como também já afirmamos, consideramos a interdisciplinaridade como um campo de questões epistemológicas e pedagógicas (construção e transmissão do conhecimento) que se coloca a partir das reflexões sobre os limites da especialização. Nenhum dos três filósofos usa o termo, ou sequer tem um equivalente que se lhe possa associar. Além disso, o termo é demasiadamente polissêmico. Em estudo bastante amplo sobre a questão, Olga Pombo (2004) propõe cinco formas tipológicas de práticas interdisciplinares. Fiquemos com uma delas, a prática de cruzamento ${ }^{3}$, que consiste em "problemas que, tendo sua origem numa determinada disciplina, irradiam para outras, invadem outros domínios, circulam, revelam-se enquanto 'problemas indisciplinados"' [destaques no original] (p. 93).

Podemos associar essa definição interdisciplinar pela prática de cruzamento tanto ao apelo de Nietzsche para que o tema dos valores fosse analisado desde muitos pontos de vista de diferentes áreas, quanto ao argumento de Adorno, segundo quem a compreensão dos poemas de Schiller torna-se mais ampla quando vistos à luz das influências que Kant exerceu sobre o poeta. A diferença, parece-nos, consiste em que para Nietzsche a filosofia tem o papel de ser o fio condutor dos demais estudos feitos pelas outras disciplinas, enquanto para Adorno ela, a filosofia, se coloca como uma disciplina ao lado de outras, em diálogo profícuo. Seja como for, o que os dois filósofos postulam é o caráter dialógico da própria filosofia, que não pode prescindir de estar em permanente contato com outras áreas do conhecimento. $\mathrm{O}$ trabalho filosófico, per se, depende dessa interlocução, haja vista seus "interesses”" serem por natureza constituídos por "metodologias" que, tendo surgido em seu campo de visão, ganharam cidadania também em outros lugares. Daí a noção de filosofia da arte, filosofia da música, filosofia da ciência e assim por diante.

Nesse sentido, Adorno considera que, mesmo sendo possível elaborar uma pesquisa em filosofia concentrando-se apenas na análise dos textos e dos argumentos de um autor, é impossível compreender em sua real dimensão o alcance desses argumentos, se não se conhece o horizonte para onde mira o filósofo, o historiador da filosofia e, em última instância, o estudante de filosofia. Um outro caso mencionado por Adorno é ilustrativo dessa relação da filosofia como prática de uma disciplina especializada entre outras, bem como o

\footnotetext{
3 As outras quatro práticas são: importação, convergência, descentração e comprometimento (p. 92 ss.). Também no final do livro, Olga Pombo traz um vocabulário sobre interdisciplinaridade (pp. 161-171).
} 


\section{pro.posições}

confronto com essa perspectiva reducionista, que o filósofo detecta como uma "ausência de formação cultural [Bildung]" (Adorno, 2003, p. 63). Trata-se do caso de uma estudante com aspirações à docência que escolheu ser avaliada na prova oral acerca de Henri Bergson. O examinador, buscando ampliar o debate para o contexto histórico-cultural, questionou qual teria sido o movimento a que pertenciam os pintores contemporâneos àquele filósofo francês. A primeira resposta foi "naturalista". Embora citasse corretamente alguns nomes da pintura, como Manet e Monet, a candidata não sabia que pertenciam ao impressionismo. Embora não tivesse escolhido esse movimento artístico como tema, mas apenas Bergson, Adorno considera importante saber fazer a relação entre a filosofia da vida e o impressionismo. No seu entender, quem não compreende nada disso, também não pode compreender Bergson. Nesse aspecto, se podemos concluir que seu diagnóstico revela uma certa impossibilidade de isolamento no trato das questões filosóficas, descoladas, por exemplo, do contexto histórico-cultural, também é verdade que são precárias as instruções de como isso poderia ser mudado. Uma questão, enfim, que julgamos ser do âmbito da transmissão do conhecimento interdisciplinar.

Foge ao objetivo deste texto apontar alguns possíveis caminhos para uma formação interdisciplinar, o que não impede de sugerir que há alguns modos em que aquela prática de cruzamento possa ocorrer, a começar por um ímpeto de conhecimento em que cada um considere sua especialização o centro do mundo. Já o fato de uma estudante de Bergson interessar-se pela pintura impressionista, ou um estudante de Schiller procurar ler Kant, significaria uma abertura de porta, uma ampliação da própria formação. Aí não interessa muito, a princípio, se essa tentativa de ampliação deve ser considerada multi, inter, pluri ou transdisciplinar. O mais importante é um desejo que demonstra a insatisfação com a formação do especialista tal como ela vem sendo praticada desde o século XIX.

Adorno (2003, p. 64) chama esse desejo de amor, alertando para não ser mal interpretado quanto a esse apelo. O desejo, seja ele o amor ou outro, poderia traduzir finalmente um pathos do conhecimento, aquele ímpeto que não se contenta ante o olhar do especialista. E, mais uma vez, o alerta de Adorno para não ser mal-entendido ganha um caráter especial, se pensarmos que a busca por outra forma de construção e transmissão do conhecimento, que aqui chamamos de interdisciplinar, não seja movida por uma espécie de entusiasmo que, ao fim das contas, querendo alçar um voo muito alto, acaba por perder o chão onde se apoiar. Nesse sentido, também o testemunho de Olga Pombo pode nos auxiliar sobre esse ponto. Se é verdade que a busca por uma unidade da ciência tornou-se uma 


\section{pro.posıções}

necessidade real desde algumas décadas, é preciso reconhecer que opera aí uma lógica de desenvolvimento que torna as condições de possibilidades dependente do próprio percurso da especialização. O conhecimento científico, tal como o entendemos, afirma Olga Pombo (2004), só foi possível graças à especialização (pp. 133-134). Por outro lado, a busca por interdisciplinaridade, quando não reconhece essa situação, acaba por tornar-se um problema para o próprio conhecimento.

É certo que ... muitas vezes a prática da interdisciplinaridade (ou daquilo que passa por esse nome) pode apenas servir para dar cobertura a uma fuga face às exigências e dificuldades do ensino de uma disciplina. Ela transforma-se então num subterfúgio que pretende evitar os rigores da aplicação sistemática de uma metodologia disciplinar, ardil por intermédio do qual se procura substituir a paciência de um ensino lento, exigente e rigoroso, por um discurso de generalidades, por um saltitar inconsequente e irresponsável de um domínio disciplinar para outro. Nesse sentido, é necessário reconhecer que, com alguma frequência, a palavra interdisciplinaridade é sinônimo de superficialidade, diletantismo, generalização abusiva, falta de solidez e mesmo incompetência de um professor, que assim revela o quanto ele mesmo é já vítima do sistema de ensino que diz pretender reformular. (Pombo, 2004, p. 122)

Palavras fortes que apontam os descaminhos para onde pode seguir a busca por interdisciplinaridade. Se, como sinaliza Adorno, a especialização, quando se fecha em si mesma, é uma limitação para o trabalho filosófico - visto tornar-se incompreensível um texto que esteja isolado do horizonte mais amplo em que foi produzido -, a abertura necessária para uma formação cultural, histórica, científica não pode prescindir daquilo que a especialização conseguiu sedimentar com muito esforço. Como vimos, esse é um alerta que o próprio Adorno faz, agora retomado noutro contexto e com mais força por Olga Pombo. Como em todas as disciplinas, a formação do especialista, com o rigor de cada metodologia necessária, deve ser o alicerce mesmo onde a produção do conhecimento deve erguer-se. A abertura à formação cultural, científica, histórica pode ser feita em diálogo com a conquista anterior do trabalho do especialista, estabelecendo sempre um cruzamento cuja condução esteja dada pelas virtudes que o trabalho disciplinar produz. Sem essa aquisição prévia (ou eventualmente posterior), corre-se o risco de a interdisciplinaridade resvalar naquela superficialidade e diletantismo, aquele "saltitar inconsequente e irresponsável de um domínio disciplinar para outro" (Pombo, 2004, p. 122). Talvez uma das explicações possíveis para essa situação a que pode conduzir a interdisciplinaridade seja uma caça às bruxas promovida contra o trabalho do especialista, numa tentativa de jogar fora a criança junto com a água do banho. 


\section{pro.posições}

No caso da filosofia, como todo texto filosófico já está, per se, marcado pela abertura ao diálogo, ao cruzamento de perspectivas com outras áreas do conhecimento, é necessário que a formação do especialista em filosofia seja contemplada por uma ampliação do espectro do saber. E, por extensão, no contato necessário com outras áreas e seus especialistas, o trabalho filosófico deve consistir em não deixar a filosofia tornar-se um adereço, uma protagonista do diletantismo.

\section{Referências Bibliográficas}

Adorno, T. (2003). A filosofia e os professores. In A. Theodor, Educação e emancipação (pp. 51-74). São Paulo: Paz e terra.

Bertalanffy, L. (1969). General system theory - foundations, development, applications. Nova Iorque: George Braziller.

Descartes, R. (1973). Discurso do método. In R. Descartes, Obras escolhidas. São Paulo: DIFEL.

Descartes, R. (2007). Regras para a orientação do espírito. São Paulo: Martins Fontes.

Fazenda, I. (2011). Integração e interdisciplinaridade no ensino brasileiro. São Paulo: Loyola.

Gusdorf, G. (1995, abril/junho). Passado, presente, futuro da pesquisa interdisciplinar. Tempo Brasileiro, 121, 7-27.

Kuhn, T. (2001). A estrutura das revoluções científicas. São Paulo: Perspectiva.

Morin, E. (1999). Os desafios da complexidade. In E. Morin (Org.), A religação dos saberes (pp. 559-567). Rio de Janeiro: Bertrand Brasil. 


\section{pro.posições}

Nietzsche, F. (1992). Além do bem e do mal. São Paulo: Companhia das Letras.

Nietzsche, F. (1998). Genealogia da moral. São Paulo: Companhia das Letras.

Nietzsche, F. (2003). Sämtliche Briefe. Kritische Studienausgabe. Berlin/München: De Gruyter/dtv, (Band 3).

Ortega y Gasset, J. (1966). La rebelión de las das masas. In J. Ortega y Gasset, Obras Completas (vol. 4). Madri: Revista do Ocidente.

Piaget, J. (1970). Problèmes généraux de la recherche interdisciplinaire et mécanismes communs. In J. Piaget, Epistémologie des sciences de l'bomme (pp. 251-377). Paris: Gallimard.

Pombo, O. (2004). Interdisciplinaridade: ambições e limites. Lisboa: Relógio D’Água.

Sloterdijk, P. (1989). Thinker on stage. Nietzsche's materialism. Minnesota: University of Minnesota Press.

Wilamowitz-Möllendorff, U. (2005). Filologia do futuro, primeira parte. In R. Machado (Org.), Nietasche e a polêmica sobre O Nascimento da Tragédia (pp. 55-78). Rio de Janeiro: Jorge Zahar.

Submetido à avaliação em 18 de fevereiro de 2016; aprovado para publicação em 29 de junho de 2016. 